\title{
PENGENALAN POLA CUACA MARITIM (CURAH HUJAN, TINGGI GELOMBANG DAN KECEPATAN ARUS) DENGAN METODE ADAPTIVE NEURO FUZZY INFERENCE SYSTEM (ANFIS) PADA JALUR PELAYARAN SURABAYA-MAKASAR
}

\author{
Oleh: \\ Riska Lutfiana $^{1}$, M.Tirono ${ }^{2}$
}

\begin{abstract}
ABSTRAK: Dalam proses pelayaran, selain kesalahan manusia, faktor cuaca juga sangat berpengaruh dalam menentukan keselamatan kapal. Sehingga pola pengenalan cuaca maritim yang dalam hal ini meliputi kecepatan arus, tinggi gelombang dan curah hujan diolah untuk nantinya digunakan sebagai rekomendasi keselamatan pelayaran kapal. Hasil pengujian pengenalan pola cuaca maritime menggunakan ANFIS, didapatkan hasil paling mendekati keakuratan pada pengujian nilai keluaran tinggi gelombang, dimana diperoleh nilai error training sebesar 0.1. sedangkan pada pengenalan pola kecepatan arus memiliki nilai error training sebesar 0.7, pada data pengenalan pola terakhir yaitu nilai curah hujan dengan nilai error training yang sangat besar yaitu 9.01, hal ini dikarenakan data yang digunakan dalam proses pengenalan pola curah hujan merupakan data harian, berbeda dengan 2 variabel sebelumnya yang menggunakan data pengenalan pola perjam, karena dalam hal ini ANFIS sangat peka terhadap jumlah data.
\end{abstract}

Kata Kunci: ANFIS, Pengenalan Pola, Cuaca Maritim

\begin{abstract}
ABSTRACK: In the process ofshipping, in addition to human error, weather was also very influential factor in determining the safety of the ship. So that the maritim weather pattern recognition which in this caseincludes thecurrent speed, wave height and rain fall will be processed for useas acruise ship safety recommendations. Recognitionof test resultsusing ANFIS maritime weather patterns, the results obtained intesting the accuracy of the closes thigher value of output wave, which earned value training error of 0.1 . where as the flow velocity pattern recogniti on training error valueof 0.7 , the final pattern recognition of data that rain fall values with values that are very large training error is 9,01 , this is because the data used in the precipitation pattern recognition process is daily data, in contrast with 2 previous variables using pattern recognition of data each hour, because in this case the ANFIS is very sensitive to the amount of data.
\end{abstract}

Keywords: ANFIS, Pattern Recognition, Weather Maritime

\section{PENDAHULUAN}

Cuaca buruk sangat ditakuti di dunia pelayaran karena akibatnya yang bisa menimbulkan berbagai kecelakaan di tengah laut seperti kapal karam atau terdampar yang akhirnya akan menimbulkan banyak korban jiwa. Meningkatnya frekuensi kejadian kecelakaan transportasi laut di Indonesia akhir-akhir ini semakin lama semakin memprihatinkan. Beberapa kejadian kecelakaan yang dialami transportasi laut, baik tenggelamnya kapal maupun tabrakan antar kapal. Bila dilihat dari faktor penyebab terjadinya kecelakaan karena disebabkan kesalahan manusia (human error) 41\%, alam (force majeur) 38\% dan akibat struktur kapal (hull structure) $21 \%$. [3]

1,2 JurusanFisikaUniversitas Islam Negeri (UIN) Maulana Malik Ibrahim Malang 
Kecelakaan dalam pelayaran yang terjadi karena faktor manusia merupakan faktor yang paling besar mempengaruhi terjadinya kecelakaan pelayaran, yang antara lain meliputi kecerobohan didalam menjalankan kapal, kurang mampunya awak kapal dalam menguasai berbagai permasalahan yang mungkin timbul dalam pelayaran kapal, dan bisa juga terjadi kesalahan secara sadar muatan kapal yang terlalu berlebihan. Faktor teknis biasanya terkait dengan kekurang cermatan di dalam desain kapal, penelantaran perawatan kapal sehingga mengakibatkan kerusakan kapal atau bagian-bagian kapal yang menyebabkan kapal mengalami kecelakaan. Selanjutnya faktor alam atau cuaca buruk yang merupakan permasalahan dan seringkali dianggap sebagai penyebab utama dalam kecelakaan laut. Permasalahan yang biasanya dialami adalah badai, gelombang yang tinggi yang dipengaruhi oleh musim, arus yang besar, juga kabut yang mengakibatkan jarak pandang yang terbatas. [2]

Fenomena cuaca ekstrim yang terjadi sejak awal tahun hingga saat ini merupakan suatu kondisi anomali cuaca dari yang biasanya terjadi dimana periode waktu atau bulan yang seharusnya cuacanya cerah menjadi sebaliknya. Anomali kondisi cuaca ini disebabkan oleh adanya efek Pemanasan Global yang ditandai gejala pergantian Musim yang susah diprediksi, hujan badai sering terjadi dimana-mana, sering terjadi angin puting beliung, banjir dan kekeringan terjadi pada waktu yang bersamaan, dan tidak jarang menyebabkan kecelakaan dalam bidang pelayaran.

Sistem neuro-fuzzy terdiri atas lima lapisan dengan fungsi yang berbeda untuk tiap lapisannya. Tiap lapisan terdiri atas beberapa simpul yang dilambangkan dengan kotak atau lingkaran. Lambang kotak menyatakan simpul adaptif artinya nilai parameternya bisa berubah dengan pembelajaran dan lambang lingkaran menyatakan simpul nonadaptif yang nilainya tetap. [1]

Tujuan dari penelitian ini dapat merancang Pengenalan Pola Cuaca Maritim (Curah Hujan, Tinggi Gelombang dan Kecepatan Arus) dengan Menggunakan Adaptive Neuro Fuzzy Inference System (ANFIS), yang selanjutnya bisa didapatkan pola cuaca maritime pada jalur pelayaran Surabaya-Makasar.

Sesuai dengan alur penelitian seperti yang telah ditunjukkan oleh gambar 3.1, urutan pelaksanaan penelitiandimulai dari studi literatur. Pada tahapan ini dipelajari mengenai terjadinya gelombang laut, arus laut dan curahhujan sehingga menemukan hubungan antara kelayakan pelayaran yang kaitannya dengan cuaca. Selain itu juga mempelajari jurnaljurnal mengenai penelitian sebelumnya. Selanjutnya dilakukan identifikasi masalah yang hubungannya dengan kelayakan pelayaran Surabaya-Makasar yang kemudian membawa ke tahap selanjutnya yaitu pengumpulan data. Data yang digunakan merupakan data unsur cuaca selama dua tahun yang dimulai dari Januari 2011 sampai Desember 2012 yang terdiri dari 7 variabel. Variabel cuaca ini diukur dam direkam oleh BMKG II Perak Surabaya. Data yang terekam ini di training agar didapatkan parameter premis awal pada model ANFIS. Kemudian dilakukan perancangan model ANFIS menggunakan software Matlab 7.6, dimana pada tahapan ini software digunakan sebagai alat bantu untuk melakukan training model sehingga didapatkan model cuaca yang sesuai. Parameter yang digunakan untuk mengetahui performansi model cuaca ini yaitu dengan melihat Root Mean Square Error (RMSE) dari validasi model yang dilakukan. 
Setelah hasil validasi memenuhi kriteria, maka model akhir cuaca berbasis ANFIS diimplementasikan ke dalam bentuk software. Perancangan software ini menggunakan Bahasa pemrograman Matlabjuga. Setelah software pengenalanpolacuaca selesai dibuat, dilakukan simulasi yaitu dengan memberikan inputan data cuaca hasil pengukuran. Hasil prediksi dari software ini dibandingkan dengan hasil pengukuran sebenarnya (validasi). Dan yang terakhir, dilakukan analisis mengenai kinerja dan ketepatan prediksi sistem ini, selanjutya dibuat laporan hasil penelitian ini.

\section{HASIL DAN PEMBAHASAN}

\section{Kecepatan Arus}

Di dalam dunia pelayaran, tidak bisa dipungkiri bahwa kecepatan arus merupakan salah satu pokok penting yang harus diamati dan diperhatikan sebagai salah satu upaya untuk menentukan layak atau tidaknya kapal untuk berlayar. Diabaikannya salah satu variable ini akan berdampak buruk pada keamanan kapal dalam proses pelayarannya, sehingga kali ini dibahas kecepatan arus sebagai salah satu pokok penting yang berperan dalam proses pelayaran. Dalam hal ini peneliti akan melakukan pembacaan pola dengan mengamati data yang telah direkam perjam selama 2 tahun ke belakang, yaitu antara tahun 2011 hingga tahun 2012 dengan menggunakan adaptive neuro inference system (ANFIS) untuk melatih data tersebut. Pada grafik 1 berikut ini ditampilkan data sebelum diolah, data ditampilkan dalam 2 tahunsekaligus.

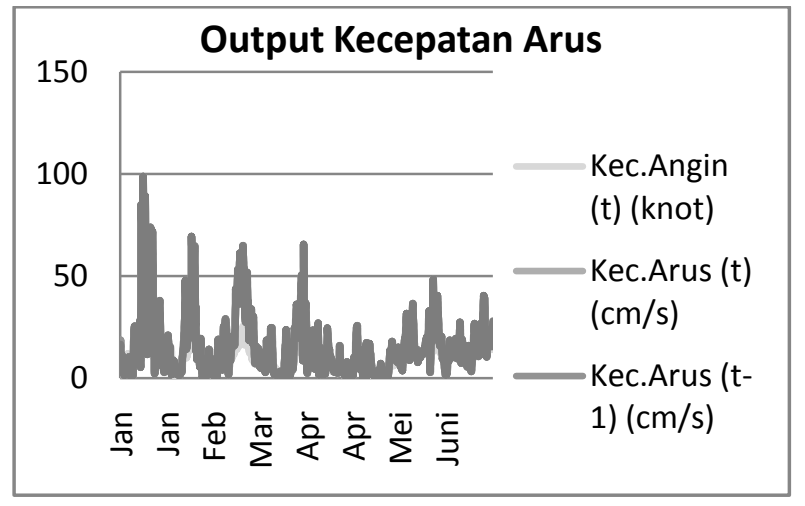

Gambar 1. Grafik Input OutputKecepatan Arus Satu Jam Setelahnya (Data2 tahun)

Dari proses pengenalan pola kecepatan arus untuk satu jam ke depan, nilai error yang diperoleh adalah sebesar 0.69 , proses pengenalan pola akan jauh lebih baik jika memiliki niai error yang mendekati nol, dalam hal ini ANFIS peka terhadap jumlah input data, jadi semakin banyak jumlah data yang diinputkan untuk proses training, maka akan membantu untuk mengurangi besarnya tingkat error yang dihasilkan. Seperti yang terlihat pada table 2 dibawah ini, table 2 merupakan table ANFIS untuk pengenalan pola dengan keluaran data berupa kecepatan arus satu jam berikutnya. Terlihat jumlah data masing-masing variabel yang digunakan sebagai data input maupun output beserta jumlah data validasi dan besar nilai RMSE trainingnya. 


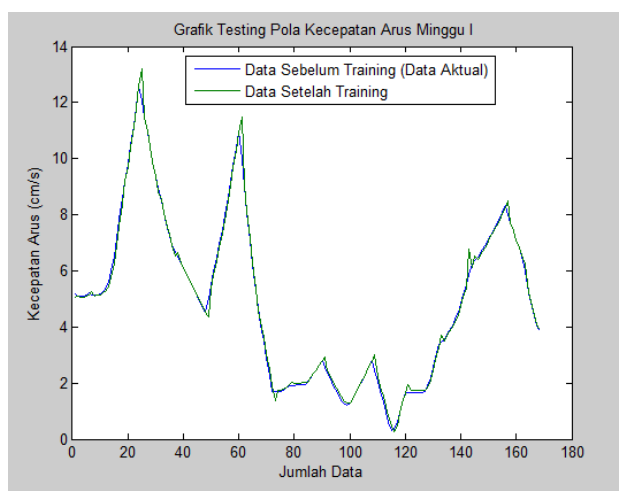

Gambar 2. Plot Data Testing Bulan Desember 2012 Minggu Pertama

Perbedaan bentuk grafik yang menonjol terlihat pada data ke 134, di mana didapatkan nilai keluaran hasil pengenalan pola yang jauh lebih tinggi dibandingkan nilai keluaran data sebenarnya. Hal ini dipengaruhi dari adanya tingkat kesalahan dari proses pengenalan pola yang dilakukan, karena sistem masih memiliki nilai error yaitu sebesar 0.69 .

\section{Tinggi Gelombang}

Besarnya ombak akan berpengaruh pada keseimbangan kapal dalam berlayar. Pada penelitian kali ini, faktor yang diperhatikan pada pengaruh tunggi rendahnya ombak salah satunya adalah variabel kecepatan angin. Data input output ditampilkan dalam grafik per 2 tahun seperti yang terlihat pada gambar 4.3.

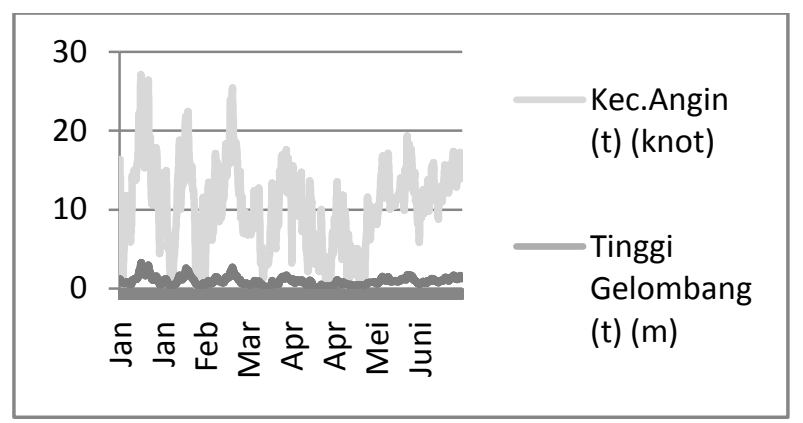

Gambar 3. Grafik Input Output KecepatanArus Satu Jam Setelahnya (Data 2 tahun)

Hasil dari output pengenalan pola yang diperoleh data dibandingkan dengan data realita sebelum proses pengenalan pola dilakukan. Seperti yang terlihat pada gambar 4 .

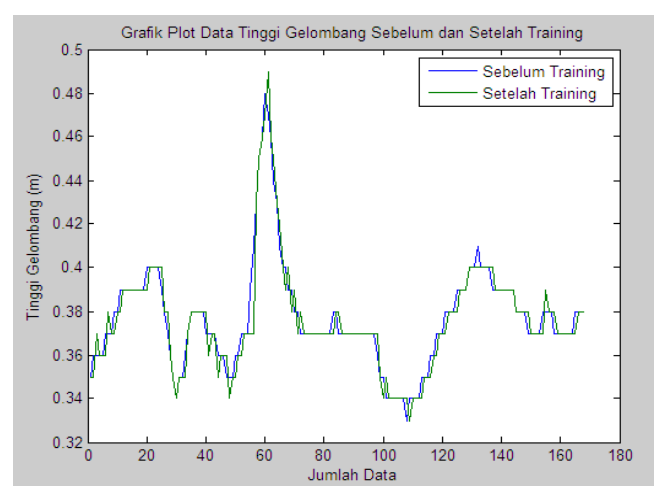

Gambar 4. Plot Data Testing BulanDesember 2012 Minggu Pertama 
Dari pemodelan data hasil training ANFIS yang dibandingkan dengan data aktual (sebenarnya) dapat dilihat pada grafik ploting di atas, dimana grafik berwarna biru merupakan perwakilan data aktual atau data asli sebelum ditraining dan grafik hijau merupakan perwakilan data hasil training ANFIS. Dari perubahan setiap titik pada grafik menunjukkan pola yang hampir sama, dimana data hasil pengolahan ANFIS berjalan mengikuti pola data sebenarnya

\section{Curah Hujan}

Dari beberapa sumber yang telah dipelajari, untuk menentukan nilai curah hujan bisa dengan mempertimbangkan 3 nilai variable yang akan diinputkan, sehingga terdapat korelasi dari ketiga variable tersebut yang akhirnya disimpulkan besarnya nilai curah hujan. Ketiga variabel tersebut diantaranya data kecepatan angin, nilai suhu atau temperature dan nilai kelembapan udara.Berbeda dari pengolahan data pada keluaran kecepatan arus dan tinggi gelombang, data yang diinputkan merupakan data yang direkam selama kurun waktu 2 tahun, mulai dari tahun 2011 hingga tahun 2012. Sehingga jumlah data yang diinputkan pada masing-masing variable berjumlah 731 data.

Berikut data yang diolah dalam menentukan nilai curah hujan yang ditampilkan dalam bentuk grafik.Data ditampilkandalam 2 tahunsekaligus seperti yang terlihat pada gambar 5 .

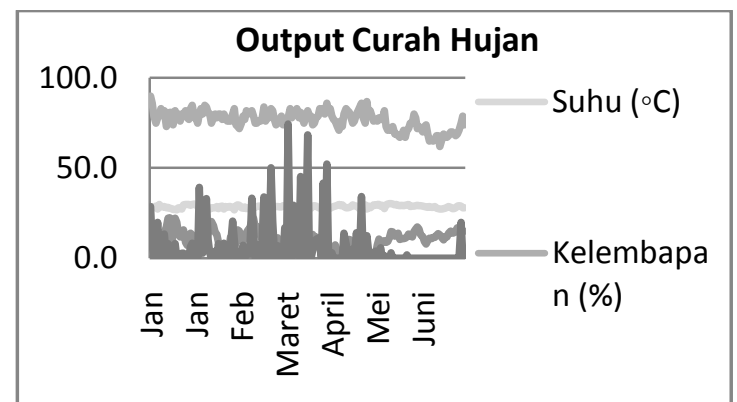

Gambar 5. Grafik Input Output Curah Hujan (Data 2 tahun)

Nilai error dapat diminimalisir dengan benar-benar memerhatikan masukan data yang akan diolah agar proses pengenala data dapat berjalan dengan baik dan menghasilkan pola data yang memiliki tingkat kevalidan yang tinggi. Gambar 6 di bawah ini merupakan grafik validasi sistem pengenalan pola curah hujan.

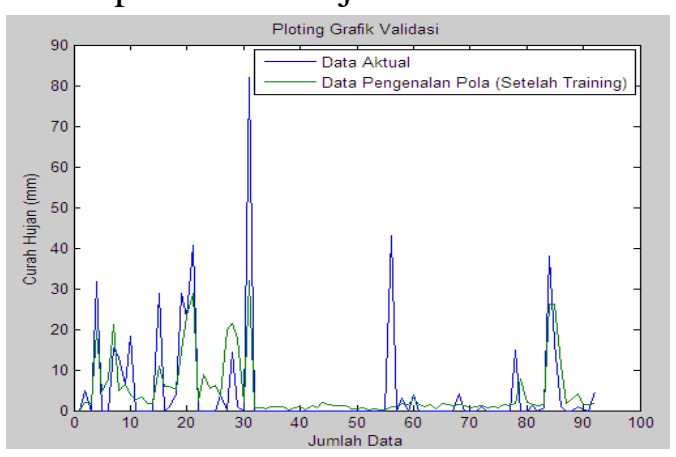

Gambar 6. Grafik Validasi Data Curah Hujan Sebelum dan Sesudah Training Bulan Oktober sampai Desember 2012 
Dari pemodelan data hasil training ANFIS yang dibandingkan dengan data aktual (sebenarnya) dapat dilihat pada grafik ploting gambar 6 di atas, dimana grafik berwarna biru merupakan data actual atau data asli sebelum ditraining dan grafik hijau merupakan data hasil training ANFIS. Dari perubahan setiap titik pada grafik menunjukkan pola yang berbeda, dimana data hasil pengolahan ANFIS tidak berjalan mengikuti pola data sebenarnya.

\section{KESIMPULAN}

Dari penelitian yang telah dilakukan dapat disimpulkan bahwa pola cuaca, khususnya pada pola curah hujan, ketingian gelombang laut dan kecepatan arus laut dapat diamati dan dipelajari pola yang terbentuk, dari sini dirancang Pengenalan Pola Cuaca Maritim (Curah Hujan, Tinggi Gelombang dan Kecepatan Arus) dengan Menggunakan Adaptive Neuro Fuzzy Inference System (ANFIS), yang selanjutnya bisa didapatkan pola cuaca maritime pada jalur pelayaran Surabaya-Makasar.

\section{DAFTAR PUSTAKA}

[1] Fossen,thor.I.1994.Guidance and Control of Ocean Vehicles. Chichester: John Wiley \& Sons.Ltd

[2] Candra, Ardian. 2010. Tugas Akhir:Perancangan Model Adaptive Nuro Fuzzy Inference System untuk Memprediksi Cuaca Maritim. Teknik Fisika-FTI-ITS Surabaya

[3] Sutomo, Heru, dkk. Menempatkan kembali keselamatan menuju transportasi yang Bermartabat 1,2,3 langkah volume 2. Masyarakat Transportasi Indonesia (MTI) bekerjasama dengan Pusat Studi Transportasi dan Logistik (PUSTRAL) UGM.Yogyakarta. 